\title{
MÉTODO DE INSPEÇÃO SISTEMÁTICO DE USABILIDADE UNIVERSAL NA ARQUITETURA: ESTUDO DE CASO COM AVALIAÇÃO HEURÍSTICA MODIFICADA
}

\author{
SYSTEMATIC INSPECTION METHOD OF UNIVERSAL USABILITY \\ IN ARCHITECTURE: CASE STUDY WITH MODIFIED HEURISTIC \\ EVALUATION
}

\section{Lucy Ana Vilela Staut ${ }^{1}$, Nubia Bernardi²}

RESUMO: Este artigo apresenta os resultados de um estudo de caso com avaliação através do método baseado em heurísticas modificado em conformação aos princípios do Desenho Universal, em Centro Comercial Planejado. O objetivo principal é analisar o potencial de aplicação da avaliação heurística modificada como método de inspeção de usabilidade universal, aliada ao percurso pluralístico. A avaliação apresenta três sessões subsequentes: (1) pré-entrevista, em que cinco avaliadores especialistas interdisciplinares analisam os projetos arquitetônicos do Centro Comercial Planejado em relação aos princípios do Desenho Universal e acessibilidade espacial e preenchem formulário de entrevista estruturada; (2) atividades em cenários, em que cada avaliador responde novamente o formulário no desenvolvimento de atividades pré-definidas; e (3) pós-entrevista, em que os formulários foram novamente respondidos através de reanálise dos projetos arquitetônicos. Como resultado, foi identificado que a avaliação heurística modificada pode integrar com eficácia a avaliação de projeto antes do fato e na avaliação pós-ocupação, produzindo interação entre análise de projeto arquitetônico e o uso do espaço. Assim sendo, destaca-se a necessidade de estudos mais aprofundados sobre usabilidade universal e seu uso na concepção de ambientes inclusivos. Esta pesquisa mostrou-se como etapa inicial para a avaliação de usabilidade universal na arquitetura e recomenda testes aplicados ao contexto arquitetônico, pois salientam a relevância de análise de elementos interdependentes no ambiente construído e devem ser integrados ao processo de projeto universal.

\section{PALAVRAS-CHAVE: Usabilidade; Desenho Universal; Acessibilidade; Avaliação; Heurística.}

ABSTRACT: This article presents the results of a case study evaluated through modified heuristics-based method in conformation to the Universal Design principles, in a Planned Commercial Center. The main objective is to analyze the application potential of the modified heuristic evaluation as a universal usability inspection method allied to the pluralistic method of inspection. The evaluation is composed of three subsequent sessions: (1) pre-interview, in which five expert interdisciplinary evaluators analyze the Planned Commercial Center's architectonic projects concerning the Universal Design principles and spatial accessibility and fill out a structured interview form; (2) activities in settings, in which each expert answers the form again during the development of pre-defined activities; and (3) post-interview, in which the forms were once again answered through a reanalysis of the architectonic projects. As result, it was identified that the modified heuristic evaluation can instate effectively the project evaluation before the fact and in the post-occupation evaluation, providing interaction between the architectonic project analysis and the space use. Therefore, further studies on universal usability and its use in inclusive spaces are of paramount importance. This research presented itself as an initial step for the universal usability evaluation in architecture, and recommends applied tests to the architectonic context, because they highlight the importance of interdependent elements analysis inside the constructed environment, and must be implemented to the universal project process.

KEYWORDS: Usability; Universal Design; Accessibility; Evaluation; Heuristic. 


\section{INTRODUÇÃO}

A arquitetura sempre apresentou um paradigma inicial em relação ao atendimento às expectativas dos usuários, "desde os aspectos básicos de habitabilidade até a fruição estética que esse abrigo pode proporcionar ao ser humano. Trata-se de um eterno desafio profissional para os projetistas que por vezes priorizam valores estético-formais em detrimento do desempenho do ambiente construído e sua qualidade funcional" (VOORDT; WEGEN, 2013, p. 5). Nesse contexto, mensurar um espaço não envolve apenas associações sensoriais visuais, mas apreensões cognitivas, táteis, olfativas e auditivas e outros fenômenos psiconeurológicos que qualificam o habitar e o viver humano (PAULA; SANTANA; DUARTE, 2007). Devido a essas afirmações, constata-se a extrema importância de verificar se a edificação resultante do processo de projeto atende às expectativas do usuário, ou seja, averiguar a qualidade da edificação relacionada à funcionalidade ou valor de utilidade, à facilidade de uso e aos benefícios emocionais (JORDAN, 2000) - isto é, em relação à usabilidade da edificação.

Segundo a NBR 9241-11 (ASSOCIAÇÃO BRASILEIRA DE NORMAS TÉCNICAS, 2002, p. 3), usabilidade é a "medida na qual um produto pode ser usado por usuários específicos para alcançar objetivos específicos com eficácia, eficiência e satisfação em um contexto de uso específico”. O termo "usabilidade" tem raízes na Ciência Cognitiva e começou a ser utilizado nas áreas de Psicologia e Ergonomia no início da década de 1980. A NBR ISO/IEC 9126-1 (Id., 2003) foi a primeira norma a definir o termo, ultrapassando as atribuições relacionadas ao ambiente acadêmico e integrando o vocabulário técnico de outras áreas do conhecimento, como Tecnologia da Informação e Interação Homem-Computador (DIAS, 2007). A despeito da extensa literatura sobre engenharia da usabilidade - podem-se destacar testes de usabilidade empregados na área de ergonomia de produtos (BEECHER; PAQUET, 2005; DEMIRBILEK; DEMIRKAN, 2004) -, ainda há espaço para pesquisar métodos para aplicação de testes de usabilidade no contexto do projeto arquitetônico (AFACAN; ERBUG, 2009). A usabilidade é um dos mais importantes aspectos do desempenho da edificação (KEITH, 2006), pois mede o quanto o edifício está adequado para as atividades previstas em seu interior; por isso, deve ser a meta mais importante (VOORDT; WEGEN, 2013), mas frequentemente é negligenciada. "Uma compreensão mais aprofundada do conceito de usabilidade será útil não só na avaliação de edifícios em uso, mas também numa melhor compreensão do que pode ser de conhecimento relevante para incluir no processo de projeto" (KEITH, 2006, p. 263, tradução nossa).

Nesse contexto, há referência à utilização do espaço pelo usuário: suas expectativas, suas metas, sua compreensão em relação aos processos de tomada de decisão e, principalmente, suas habilidades. A construção de um ambiente acessível e projetos de edificações que possam ser utilizados por todos são desafios a serem solucionados pelos projetistas e necessitam de medidas de usabilidade e dos critérios do Desenho Universal, pois, "no atual momento, a avaliação de desempenho com foco no Desenho Universal pode ser considerada crítica e necessita ser desenvolvida” (PREISER, 2010, p. 19). Quando as medidas de usabilidade de prática, ou seja, valor de utilidade da edificação, são definidas como amplamente utilizáveis em termos de Desenho Universal e arquitetura dos espaços, pode-se ampliar o conceito para usabilidade universal, cujo principal objetivo é permitir que o maior número possível de usuários se beneficie do acesso, do uso e da obtenção de produtos/serviços do ambiente construído na mais ampla gama de situações (AFACAN; ERBUG, 2009).

A qualidade funcional do ambiente construído tem sido cada vez mais solicitada, e a preocupação em oferecer espaços acessíveis, compreensíveis, seguros e confortáveis é cada vez mais constante. Perante essa argumentação e objetivando a qualidade funcional que as edificações devem apresentar, tornam-se necessários estudos e metodologias que avaliem as condições de 
usabilidade da edificação na prática e a acessibilidade espacial para todos os usuários, independentemente de suas habilidades.

Muitas pessoas têm dificuldades em acessar e percorrer espaços de edifícios públicos e semipúblicos, como aeroportos, hospitais, escritórios ou centros comerciais planejados. O problema pode estar relacionado aos processos mentais de cognição e percepção da organização ambiental, mas também a uma arquitetura que não compreende as necessidades oriundas das diferentes deficiências para a realização de atividades nem a cognição espacial humana (HÖLSCHER et al., 2006).

Este artigo apresenta um estudo sobre as questões casuais de nossa rotina em relação à usabilidade universal do projeto arquitetônico dos espaços: como utilizar um edifício de maneira eficiente, eficaz e satisfatória? Como chegar a determinado lugar com segurança, conforto e independência? E também indaga as questões relacionadas ao processo de projeto desses espaços amplamente utilizáveis: como ampliar o potencial de inclusão social através da melhoria da qualidade de locomoção e utilização do espaço? Como avaliar problemas de usabilidade universal do espaço arquitetônico na etapa de produto, antes do término da construção?

A pesquisa aqui relatada analisa o potencial de aplicação do método de avaliação de usabilidade modificado baseado em heurísticas, desenvolvido por Afacan e Erbug (2009), pertinente ao contexto arquitetônico. A avaliação heurística objetiva "identificar problemas de usabilidade que, posteriormente, serão analisados e corrigidos ao longo do processo de desenvolvimento" (DIAS, 2007, p. 62). Essa avaliação é realizada por especialistas em usabilidade, com base em sua experiência e competência no assunto, e o processo se dá através da avaliação baseada em heurísticas.

O objetivo geral da pesquisa foi analisar o potencial de aplicação de uma avaliação heurística modificada como método de inspeção de usabilidade universal, aliada ao percurso pluralístico. Esta pesquisa coloca-se na interface entre acessibilidade espacial e avaliação heurística, como método de inspeção sistemático de usabilidade.

\section{REFERENCIAL TEÓRICO}

Toda atividade humana necessita de um ambiente físico para ser realizada. O processo do pensar planeja o espaço construído e apresenta-se como o principal instrumento do arquiteto (HETZBERGER, 1999). Com base na teoria da percepção, o arquiteto pode empregar recursos construtivos para modificar a percepção dos indivíduos e possibilitar que o usuário utilize o espaço de maneira plena, eficiente e satisfatória, ampliando o valor de utilidade, ou seja, a usabilidade da edificação.

A sociedade contemporânea convive em ambientes modificados pelo homem, vivenciando espaços projetados com variedades de características que serão experimentadas e vivenciadas pelo usuário e promoverão diferentes impressões, "uma vez que cada indivíduo é um ser único, com suas particularidades e individualidade, mesmo pertencendo a um mesmo grupo social. Assim, cada indivíduo 'percebe', atua e reconstrói diferentemente um mesmo ambiente" (BLOWER, 2008, p. 24). O homem percebe à sua volta as características das edificações e das cidades que o rodeiam e, de maneira natural, ao se reter em alguma delas, estará formando juízo de valor em relação àquilo que vê. A experiência espacial arquitetônica se dá no interior da edificação e no espaço urbanístico; sendo assim, apenas a interpretação espacial de um edifício não é suficiente como instrumento crítico para um julgamento da obra arquitetônica (ZEVI, 2009). Cabe aos profissionais de arquitetura adotar conceitos de espaços pluridisciplinares, com abordagem psicológica, sociológica e histórica.

A percepção ambiental conduz o indivíduo à vivência e ao reconhecimento do ambiente construído. O espaço arquitetônico é percebido através dos 
sentidos e transformado em imagem mental, ou seja, converte o espaço simbólico em espaço pensado e o representa na mente. A interpretação do espaço simbólico, através da consciência e do pensamento, leva o usuário a uma tomada de decisão, transformando o espaço arquitetônico em espaço vivencial (CARLIN, 2004, p. 50). A arquitetura não pode ser vivenciada e experimentada se o usuário não se movimentar por ela, se não a percorrer, e isso se dá através da orientação e da leitura do ambiente. Diversos autores desenvolveram metodologias de leitura e interpretação do espaço urbano. Podemos citar propostas de Kevin Lynch (2010), Christian Norberg-Schulz (1975), Thomas Gordon Cullen (1971), Edmund N. Bacon (1976) e Ignasi de Solà-Morales Rubió (2002), partindo do princípio de que a percepção possibilita a compreensão do espaço construído, ou seja, sua condição geométrica e sua relação com o meio.

Várias metodologias de leitura e interpretação do espaço urbano apresentam o atributo visual como elemento principal. Mas e na ausência de visão do usuário? "Ao tratar das características físicas dos espaços e das possibilidades de acesso e uso por parte dos distintos usuários, o tema acessibilidade e Desenho Universal remete à área de estudos Ambiente e Comportamento (Environment and Behavior)" (REIS; LAY, 2010, p. 105). Prover o ambiente de informações e soluções espaciais diferenciadas para usuários com diferentes habilidades e limitações, ou seja, intervenções para qualificação da vida urbana, é um grande desafio para os arquitetos e urbanistas. Devido a essa afirmação, a demanda pelo conhecimento específico sobre a natureza das diferentes restrições e suas implicações na utilização do espaço se faz necessária. Portanto, é de extrema importância discutir "a importância da abordagem perceptiva e cognitiva para a análise espacial envolvendo a acessibilidade e Desenho Universal” (REIS; LAY, 2010, p. 105).

Entretanto, o Desenho Universal ultrapassa os requisitos mínimos para acomodar pessoas com deficiência (acessibilidade básica) determinados pela normatização que se apresenta aquém das condições ideais (boa acessibilidade e usabilidade) e exigências pertinentes ao ambiente construído. A concepção de conforto está fortemente ligada a fatores pessoais, ou seja, relaciona-se às características físicas individuais, reestruturando e recriando o conceito do homem-padrão (CAMBIAGHI; CARLETTO, 2008). O conceito do Universal Design considera a diversidade humana, respeitando as diferenças existentes entre as pessoas e garantindo a acessibilidade a todos (SILVA et al., 2008).

O termo "usabilidade" começou a ser utilizado no início da década de 1980, principalmente nas áreas de Psicologia e Ergonomia, como substituto da expressão user-friendly ${ }^{1}$ (DIAS, 2007). Segundo Nielsen e Loranger (2007), a usabilidade é um atributo de qualidade relacionado à facilidade do uso de algo. Busca elaborar produtos com design inclusivo, ou seja, que procuram atender às características e necessidades de usuários que possuem diferentes habilidades e, sendo assim, envolvem métodos e metodologias aplicadas em tarefas, considerando que a arquitetura está diretamente vinculada ao espaço físico, às suas formas e ao seu uso (KASPER; LOCH; PEREIRA, 2012). "Se um sistema está utilizável, devem-se experimentar os atributos objetivos e subjetivos de usabilidade. Os atributos objetivos de usabilidade são eficácia, capacidade de aprendizado, flexibilidade, compreensibilidade, memorização e confiabilidade. Os atributos subjetivos de usabilidade incluem atitude positiva e satisfação do usuário e do produto (sistema de atratividade)" (KOOHANG, 2004, p. 130, tradução nossa).

Pode-se considerar uma edificação com acessibilidade plena quando os usuários e visitantes não encontram dificuldades em alcançar seu destino, participar das atividades previstas e utilizar as instalações necessárias para isso. Na prática do projeto arquitetônico, a eficácia do uso e a ergonomia não são levadas em consideração, resultando em problemas verificados após a construção da edificação concluída. Essa verificação tardia surge a

Traduzido para o português como “amigável e intuitivo”. 
partir da falta de consciência do projetista da necessidade de avaliação do projeto por especialistas na fase de concepção, objetivando verificar cada decisão projetual correspondente ao Desenho Universal e usabilidade para pessoas com diversas habilidades (AFACAN; ERBUG, 2009).

No contexto arquitetônico, a avaliação "refere-se principalmente à determinação do valor do ambiente construído ou de parte dele (avaliação do produto), ou do processo de projeto, construção e gerenciamento (avaliação do processo)" (VOORDT; WEGEN, 2013, p. 142). A avaliação permite o aprimoramento da edificação através da melhoria do projeto arquitetônico, da qualidade de programas de necessidades, da construção e do gerenciamento.

A avaliação deve fazer parte da metodologia de projeto do profissional de arquitetura. Na maioria dos casos, essa avaliação tem sido realizada por meio de "métodos que englobam listas de verificação (checklists), seleção de parâmetros, classificação e atribuição de pesos, especificações escritas e índices de confiabilidade” (KOWALTOWSKI et al., 2006, p. 12).

Um dos métodos de avaliação de usabilidade utilizado para avaliação de projetos interativos é a avaliação heurística e as regras de usabilidade. Segundo Ferreira (2008, p. 450), heurística é "um conjunto de regras e métodos que visam à descoberta, à invenção, ou à resolução de problemas”. Para resolver a maioria dos problemas, as pessoas utilizam estratégias intuitivas, chamadas "heurísticas", ou seja, regras formais e linhas-guia generalizadas. A partir de 1990, a expressão "heurística" passou a ser utilizada frequentemente por Nielsen e Molich (1990), propondo um método de avaliação de usabilidade.

A avaliação heurística é um dos métodos não empíricos existentes para avaliar a usabilidade, ou seja, encontrar problemas de usabilidade durante um processo de design interativo (NIELSEN, 1993, 1994). Permite uma avaliação contínua do processo com baixo custo, envolvendo profissionais especialistas que avaliam o design com base em um conjunto de princípios de usabilidade ou heurísticas (TANAKA, 2009). Em geral, a avaliação heurística não é realizada por um único avaliador, pois segundo Nielsen (1995a, tradução nossa), "um único avaliador nunca vai ser capaz de encontrar todos os problemas de usabilidade em uma interface. Felizmente, a experiência em vários projetos diferenciados demonstrou que avaliadores diferentes encontram diversos problemas de usabilidade".

Os tópicos de usabilidade definidos por Nielsen (1993, 1995b; NILSEN; LORANGER, 2007; NIELSEN; MOLICH, 1990) a partir desse método são apresentados no Quadro 1. Nielsen (1995a) recomenda que a avaliação heurística envolva de três a cinco avaliadores interdisciplinares e especialistas em usabilidade.

Quadro 1: Versão revisada das heurísticas de Nielsen e tarefas do método de avaliação heurística

\begin{tabular}{|l|}
\hline \multicolumn{1}{|c|}{ Heurísticas de Nielsen } \\
\hline Visibilidade do status do sistema \\
\hline Compatibilidade com o mundo real \\
\hline Controle e liberdade do usuário \\
\hline Consistência e padronização \\
\hline Prevenção de erros \\
\hline Reconhecimento em vez de memorização \\
\hline Flexibilidade e eficiência de uso \\
\hline Estética de design minimalista \\
\hline Ajudar os usuários a reconhecer, diagnosticar e corrigir erros \\
\hline Help e documentação \\
\hline
\end{tabular}




\begin{tabular}{|l|l|}
\hline \multicolumn{2}{|c|}{ Avaliação heurística } \\
\hline \multicolumn{1}{|c|}{ Atividade } & \multicolumn{1}{c|}{ Tarefa } \\
\hline Preparação & $\begin{array}{l}\text { Todos os avaliadores: } \\
\text { Aprendem sobre a situação atual: usuários, domínio etc. } \\
\text { Selecionam as partes da interface que devem ser avaliadas. }\end{array}$ \\
\hline Coleta de Dados & $\begin{array}{l}\text { Cada avaliador, individualmente: } \\
\text { Inspeciona a interface para identificar violações das heurísticas. } \\
\text { Interpretação }\end{array}$ \\
$\begin{array}{l}\text { Lista os problemas encontrados pela inspeção, indicando local, } \\
\text { gravidade, justificativa e recomendações de solução. }\end{array}$ \\
\hline $\begin{array}{l}\text { Consolidação dos } \\
\text { resultados }\end{array}$ & $\begin{array}{l}\text { Todos os avaliadores: } \\
\text { Revisam os problemas encontrados, julgando sua relevância, } \\
\text { gravidade, justificativa e recomendações de solução. } \\
\text { Geram um relatório consolidado. }\end{array}$ \\
\hline
\end{tabular}

Fonte: Barbosa e Silva, 2010, p. 317-318, e Tanaka, 2009, p. 35

Afacan e Erbug (2009) relatam um método de baixo custo para avaliação de usabilidade a fim de explorar problemas de usabilidade exclusivamente a partir de desenhos do projeto arquitetônico (plantas, cortes e elevações), ou seja, o mais cedo possível no processo de projeto arquitetônico e, a partir dessa problemática, desenvolvem um estudo de avaliação heurística modificada com o objetivo de avaliar edificações em conformidade com os princípios do Desenho Universal.

O artigo fornece uma definição de usabilidade universal que se aplica ao contexto de projeto arquitetônico de um centro comercial planejado, e um estudo de caso agregou os sete princípios do Desenho Universal como um conjunto de heurísticas para obter uma avaliação da usabilidade universal (Quadro 2), objetivando alcançar um processo de avaliação rápido e que gere custo-benefício para a melhoria do projeto da edificação. Esse novo conjunto de heurísticas foi criado para refletir a inclusão do processo de concepção universal e as exigências dos sete princípios do Desenho Universal.

Quadro 2: Definições e considerações de projeto dos princípios do Desenho Universal utilizadas como heurísticas - Centro Comercial Planejado

\begin{tabular}{|l|l|l|}
\hline \multicolumn{1}{|c|}{ Princípio } & \multicolumn{1}{|c|}{ Definição } & \multicolumn{1}{|c|}{ Considerações projetuais } \\
\hline Princípio 1: Uso equitativo & $\begin{array}{l}\text { O design é útil e comercializável a qualquer grupo } \\
\text { de usuários com habilidades diversas, ou seja, pode } \\
\text { ser utilizado por pessoas com habilidades diversas, } \\
\text { evitando segregação ou discriminação. }\end{array}$ & $\begin{array}{l}\text { O centro comercial deve proporcionar } \\
\text { igualdade para todos os usuários em } \\
\text { termos de uso, compreensão, acesso, } \\
\text { privacidade, segurança e conforto. }\end{array}$ \\
\hline $\begin{array}{l}\text { Princípio 2: Flexibilidade } \\
\text { de uso }\end{array}$ & $\begin{array}{l}\text { O projeto acomoda uma ampla variedade de } \\
\text { preferências e habilidades individuais, ou seja, } \\
\text { flexibilidade no uso para habilidades diversas } \\
\text { individuais. }\end{array}$ & $\begin{array}{l}\text { O centro comercial deve propiciar } \\
\text { flexibilidade de uso e adaptabilidade } \\
\text { às condições espaciais imprevistas, e } \\
\text { propiciar alteração de seus requisitos } \\
\text { espaciais ao longo do tempo. }\end{array}$ \\
\hline $\begin{array}{l}\text { Princípio 3: Uso simples e e } \\
\text { intuitivo }\end{array}$ & $\begin{array}{l}\text { Uso do design deve ser de fácil entendimento, } \\
\text { independentemente da experiência, conhecimento, } \\
\text { proficiência de linguística ou nível atual de } \\
\text { concentração dos usuários, ou seja, simplicidade e } \\
\text { intuitividade do uso. }\end{array}$ & $\begin{array}{l}\text { O centro comercial deve ser projetado } \\
\text { para ser consistente em relação às } \\
\text { expectativas dos usuários e eliminar } \\
\text { complexidade desnecessária. }\end{array}$ \\
\hline $\begin{array}{l}\text { Princípio 4: Informação } \\
\text { perceptível }\end{array}$ & $\begin{array}{l}\text { O projeto deve comunicar de maneira eficaz a } \\
\text { informação necessária ao usuário, independentemente } \\
\text { das condições ambientais ou de suas habilidades } \\
\text { sensoriais, ou seja, percepção fácil e eficiente da } \\
\text { informação para o uso. }\end{array}$ & $\begin{array}{l}\text { O centro comercial deve proporcionar } \\
\text { contraste adequado entre a informação } \\
\text { essencial e condições de fundo. }\end{array}$ \\
\hline $\begin{array}{l}\text { Princípio 5: Tolerância minimizar os riscos e as consequências } \\
\text { ao erro }\end{array}$ & $\begin{array}{l}\text { au seja, tolerância ao erro, minimizando efeitos } \\
\text { indesejáveis pelo uso incorreto. }\end{array}$ & $\begin{array}{l}\text { Ascterísticas do projeto do centro } \\
\text { minimizar os riscos e erros, e devem } \\
\text { fornecer avisos. }\end{array}$ \\
\hline
\end{tabular}


Quadro 2: Continuação

\begin{tabular}{|l|l|l|}
\hline \multicolumn{1}{|c|}{ Princípio } & \multicolumn{1}{|c|}{ Definição } & \multicolumn{1}{c|}{ Considerações projetuais } \\
\hline $\begin{array}{l}\text { Princípio 6: Baixo esforço } \\
\text { físico }\end{array}$ & $\begin{array}{l}\text { O projeto deve ser utilizado de forma eficiente, } \\
\text { confortável e com o mínimo de fadiga, ou seja, com } \\
\text { o mínimo de esforço físico. }\end{array}$ & $\begin{array}{l}\text { As características do projeto do centro } \\
\text { comercial devem minimizar o esforço } \\
\text { físico e a fadiga. }\end{array}$ \\
\hline $\begin{array}{l}\text { Princípio 7: Tamanho } \\
\text { e espaço para } \\
\text { aproximação e uso }\end{array}$ & $\begin{array}{l}\text { Oferecer tamanho e espaços adequados para } \\
\text { aproximação, alcance, manipulação e uso, } \\
\text { independentemente do tamanho, postura ou } \\
\text { mobilidade do usuário. Ou seja, previsão de tamanho e } \\
\text { espaço para o uso em diferentes situações. }\end{array}$ & $\begin{array}{l}\text { Deve ser fornecido espaço de } \\
\text { aproximação, alcance, manipulação } \\
\text { e uso, de tamanho adequado, } \\
\text { independentemente do tamanho do corpo } \\
\text { do usuário, postura ou mobilidade. }\end{array}$ \\
\hline
\end{tabular}

Fonte: Afacan e Erbug, 2009, p. 732, tradução nossa

Segundo Afacan e Erbug (2009, p. 731, tradução nossa),

os resultados mostraram que a avaliação heurística poderia integrar, com sucesso, a avaliação de usabilidade universal na prática atual de projeto arquitetônico de duas maneiras: a) promovendo um processo iterativo de avaliação combinado com multisessões, ao contrário de depender de um avaliador e uma única sessão de avaliação, objetivando a busca do número máximo de problemas que prejudiquem a usabilidade; b) destacando a necessidade de um comitê interdisciplinar de especialistas, com carga de conhecimento, experiência e que se baseiem em regras, recomendações, princípios e/ou conceitos pré-estabelecidos.

No caso de se verificar a acessibilidade focada na usabilidade, a tarefa não é simples, devido à diversidade dos usuários. "As habilidades das pessoas mudam ao longo do tempo, e esses usuários querem ser acomodados dentro do ambiente construído da forma mais eficiente, eficaz e satisfatória possível, independentemente de sua condição de saúde, tamanho do corpo, força, experiência, poder de mobilidade ou idade” (AFACAN; ERBUG, 2009, p. 733, tradução nossa). O principal objetivo da usabilidade universal é permitir que o maior número possível de usuários se beneficie do acesso, do uso e da obtenção de produtos/serviços do ambiente construído na mais ampla gama de situações (AFACAN; ERBUG, 2009).

Nesse contexto, uma investigação mais aprofundada da avaliação heurística como método de avaliação de usabilidade proposta por esses pesquisadores se faz necessária. As definições e considerações dos princípios do Desenho Universal apresentam-se limitadas em relação às considerações projetuais. Há necessidade de verificação e complementação do instrumento de avaliação e sua aplicação.

\section{METODOLOGIA}

A pesquisa aqui descrita coloca-se na interface entre os componentes da acessibilidade espacial e a avaliação heurística como método de avaliação de usabilidade. Seu objetivo foi analisar o potencial de aplicação de uma avaliação heurística modificada como método de inspeção de usabilidade universal, aliada ao percurso pluralístico no contexto de projeto arquitetônico.

Com base no objetivo geral, a pesquisa desenvolvida é classificada como descritiva, pois visa principalmente o aprimoramento de ideias ou a descoberta de intuições. Os dados analisados foram coletados em três sessões consecutivas, a partir de um estudo de caso aplicado em um centro de compras planejado, selecionado devido à complexidade espacial e à escala.

A unidade-caso selecionada, o Centro Comercial Planejado, está implantada em um platô central de aproximadamente $150.000 \mathrm{~m}^{2}$ na região Norte do Paraná. A edificação possui forma em leque resultante de uma 
malha modular à forma do platô. Inicialmente, a intenção projetual na estrutura circulatória do conjunto era "sugerir uma sensação de novidade a cada ângulo do percurso" (CASTELNOU, 2002, p. 299). As atividades estabelecidas na configuração espacial do Centro Comercial Planejado são divididas em comércio, serviços, atividades de lazer e entretenimento, centro de eventos, laboratório de análises clínicas, parque de diversões localizado na praça de alimentação e administração do grupo empreendedor.

O Centro oferece ao público sete sanitários de uso coletivo, masculinos e femininos, fraldário e espaço família, inaugurado em 2012. Todos os sanitários possuem cabine adaptada para pessoas com deficiência. Nos sanitários da área de expansão, os sanitários adaptados, feminino e masculino, estão localizados fora dos sanitários de uso coletivo. O espaço família possui fraldário, lactário e sanitários para crianças e uma unidade para adultos. Nessa área há sanitário externo adaptado para pessoas com deficiência, possibilitando acompanhamento por pessoas de sexo diferente, solução definida no Decreto-Lei $n^{\circ} 5.296$ (BRASIL, 2004).

Para o desenvolvimento desta pesquisa, a metodologia adotada compreendeu a aplicação do método de avaliação heurística modificado, definido por Afacan e Erbug (2009), que consiste na avaliação de usabilidade do projeto arquitetônico em conformação aos princípios do Desenho Universal. Em uma avaliação heurística, Nielsen (1994) recomenda a participação de três a cinco avaliadores multidisciplinares e especialistas em usabilidade. Como requisito, o avaliador, segundo a especificidade da pesquisa, deve ser profissional na área de arquitetura e urbanismo especialista em questões de usabilidade e ergonomia no ambiente construído. Devido à inexistência de arquitetos especialistas em usabilidade na região, foram selecionados quatro arquitetos interdisciplinares, especialistas em acessibilidade, nas áreas de projeto arquitetônico, design de interiores e planejamento urbano, e um avaliador na área de construção. Segundo Afacan e Erbug (2009), a distribuição do número de avaliadores em cada disciplina deve seguir a representação proporcional da percentagem de colaboração das áreas em relação ao projeto de arquitetura de centros comerciais planejados. Seguindo essa indicação, foram selecionados dois profissionais da área de projeto arquitetônico e um profissional de design de interiores e planejamento urbano.

Propôs-se, na pesquisa, a associação da avaliação heurística ao método de inspeção ou percurso pluralístico e a conformação dos componentes da cidade universal, definidos por Danford e Tauke (2001) e utilizados na avaliação heurística, aos componentes da acessibilidade espacial, definidos por Dischinger, Ely e Piardi (2012), enfatizando a orientação espacial e o wayfinding, que se relacionam diretamente à eficácia dos outros componentes.

A avaliação foi composta por três sessões consecutivas, apresentadas a seguir (Figura 1):

Figura 1: Estrutura da avaliação heurística aplicada

Fonte: Adaptado de Afacan e Erbug, 2009, p. 732

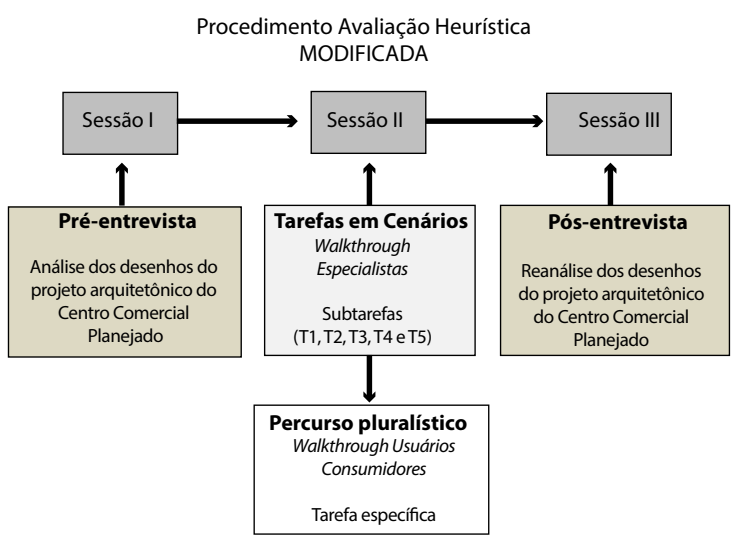

Na sessão I (avaliação em fase de projeto: pré-entrevista), um grupo de quatro arquitetos e um construtor, com conhecimentos em acessibilidade, 
foi convidado a avaliar cenários pré-definidos do projeto arquitetônico do Centro Comercial Planejado (plantas, cortes, elevações e placas de sinalização) em termos de princípios do Desenho Universal e acessibilidade espacial, heurísticas. Foi solicitado o preenchimento do primeiro formulário.

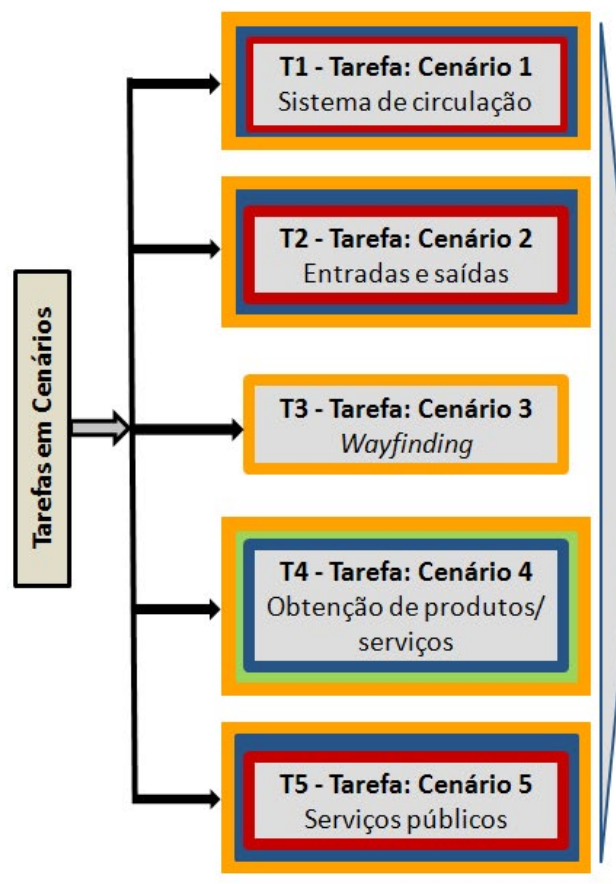

\begin{tabular}{|c|}
\hline Subtarefa 1 \\
Uso equitativo \\
Subtarefa 2 \\
Flexibilidade de uso \\
Subtarefa 3 \\
Uso intuitivo \\
\\
Subtarefa 4 \\
Informação perceptível \\
Subtarefa 5 \\
Tolerância ao erro \\
Subtarefa 6 \\
Baixo esforço físico \\
Subtarefa 7 \\
\end{tabular}

A sessão II (avaliação pós-ocupação: tarefas em cenários) foi dividida em duas etapas:

- Sessão II-A: walkthrough ${ }^{2}$ de especialistas ${ }^{3}$, ou seja, realização individual de tarefas em cenários pré-definidos (Figura 2). 0 grupo de avaliadores foi convidado a percorrer os cenários prédefinidos e avaliá-los conforme os princípios do Desenho Universal e acessibilidade espacial, heurísticas. Foi solicitado o preenchimento do segundo formulário.

- Sessão II-B: percurso pluralístico ${ }^{4}$ em tarefas específicas walkthrough de usuários consumidores, ou seja, realização individual de tarefas em cenários pré-definidos. Com o objetivo de buscar informações referentes às dificuldades de usabilidade do espaço pelos consumidores, recorreu-se à utilização do método de inspeção ou percurso pluralístico, colocando o usuário consumidor na análise de um cenário de tarefas pré-determinado. Para o walkthrough, o grupo de usuários consumidores foi determinado, pelas avaliações realizadas pelos especialistas, como grupo com maior usabilidade satisfatória encontrada. São eles: pessoa com deficiência motora (cadeirante), mãe com carrinho de bebê e pessoa idosa.

Walkthrough: "método de análise que combina simultaneamente uma observação com uma entrevista" através de um percurso estruturado (RHEINGANTZ et al., 2009, p. 23).

Walkthrough de especialistas: um grupo de especialistas é organizado objetivando a análise de "um conjunto determinado de um ambiente ou edifício, tais como condições físicas, utilidade de algum aspecto, fator ou atributo específico" (RHEINGANTZ et al., 2009, p. 27).

$4 \quad$ Método de inspeção pluralístico: consiste em "reuniões entre usuários, projetistas de sistemas e especialistas em usabilidade, em que são analisados os cenários das tarefas e avaliados cada um dos elementos da interação do usuário com o sistema” (DIAS, 2007, p. 48).

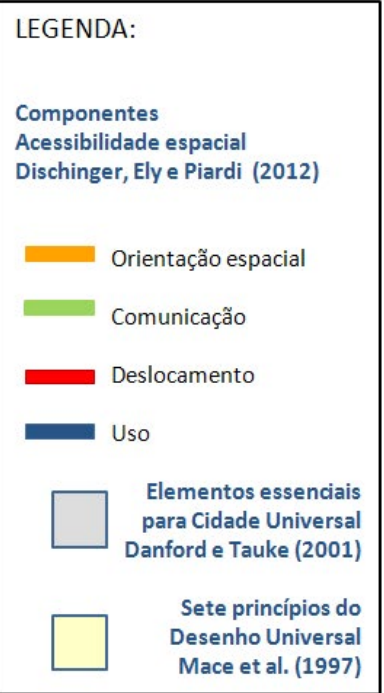

Figura 2: Relação entre tarefas e heurísticas

Fonte: Adaptado de Afacan e Erbug, 2009, p. 733 
Na sessão III (avaliação em fase de projeto: pós-entrevista), o grupo de especialistas foi convidado a reavaliar os cenários pré-definidos no projeto arquitetônico do Centro Comercial Planejado (plantas, cortes, elevações e placas de sinalização) em termos de princípios do Desenho Universal e acessibilidade espacial, heurísticas. Foi solicitado o preenchimento do terceiro formulário.

Para a coleta dos dados, o instrumento de avaliação heurística caracterizou-se como entrevista estruturada e apresentou-se como um roteiro previamente programado, em sistemas de formulários impressos, os quais possibilitaram a classificação de problemas de usabilidade e contribuíram para a avaliação da usabilidade universal do espaço construído.

O formulário de avaliação foi estruturado com base na entrevista aberta idealizada pelos pesquisadores Afacan e Erbug (2009). Procurou-se destacar os cenários de tarefas conformados com as heurísticas, diretrizes dos princípios do Desenho Universal, ou seja, elementos-chave que devem estar presentes em um projeto e componentes da acessibilidade espacial, heurística não utilizada pelos pesquisadores-referência.

Inicialmente, foi desenvolvida a apresentação da pesquisa e colhida a assinatura do Termo de Consentimento Livre e Esclarecido, pretendendo informar as razões da avaliação, descrever a justificativa e seus objetivos adequadamente e, principalmente, garantir o sigilo de dados confidenciais ou que, de algum modo, pudessem provocar constrangimentos ou prejuízos aos voluntários e especialistas. Foram apresentadas conceituações iniciais sobre o método de avaliação heurística modificado, usabilidade, Desenho Universal, acessibilidade espacial e avaliação heurística para o desenvolvimento da avaliação e preenchimento do formulário fornecido pelo pesquisador aos avaliadores. Os formulários foram preenchidos pelos avaliadores individualmente e as observações relatadas durante a avaliação pelos especialistas foram anotadas pelo pesquisador.

O formulário de avaliação foi desenvolvido para cada um dos cinco elementos da Cidade Universal (DANFORD; TAUKE, 2001), relacionados aos sete princípios do Desenho Universal (vide Figura 2) e aos componentes de acessibilidade espacial (orientação espacial, deslocamento, comunicação e uso). Os cinco elementos da Cidade Universal são: sistema de circulação (Elemento 1); entradas e saídas (Elemento 2); wayfinding (Elemento 3); obtenção de produtos e serviços (Elemento 4) e serviços públicos (Elemento 5).

Os componentes da acessibilidade espacial foram representados por cores: orientação espacial (laranja); deslocamento (vermelho); comunicação (verde) e uso (azul).

O formulário de avaliação foi diagramado utilizando-se siglas e simbologias que identificassem, de forma crescente, a natureza e o grau dos problemas de usabilidade que foram determinados, do menor grau para o maior grau de problemas. O formulário apresentou-se da seguinte maneira:

- Avaliação positiva, usabilidade satisfatória (US): os elementos avaliados proporcionam eficácia, eficiência e satisfação nas condições igualitárias de uso a todos os usuários. Símbolo (++) e cor verde clara.

- Problemas de usabilidade fracos, permite o uso com pequenas restrições (PUPR): os elementos avaliados proporcionam pequenas restrições em relação à eficácia, eficiência e satisfação. Símbolo (+ -) e cor amarela de tonalidade clara.

- Problemas de usabilidade médios, permite o uso com dificuldade (PUD): os elementos avaliados proporcionam problemas medianos em relação à eficácia, eficiência e satisfação. Símbolo (- +) e cor amarela de tonalidade média.

- Problemas de usabilidade graves (PUG): os elementos avaliados proporcionam problemas graves em relação à eficácia, eficiência e satisfação. Símbolo (- -) e cor amarela de tonalidade escura. 
Segue a demonstração do formulário com o Elemento 1, sistema de circulação, relacionado ao Princípio 1 do Desenho Universal, uso equitativo - igualdade (Figuras 3 e 4).

\section{CENÁRIO DE TAREFAS}

\begin{tabular}{|c|c|c|c|c|c|c|c|}
\hline $\begin{array}{l}\text { Elemento 1: } \\
\text { Sistema de } \\
\text { circulação }\end{array}$ & \multicolumn{3}{|c|}{$\begin{array}{l}\text { UTILIZANDO TODOS OS CORREDORES, ESCADA, ESCADA ROLANTE E } \\
\text { ELEVADORES }\end{array}$} & \multirow{2}{*}{\multicolumn{4}{|c|}{$\begin{array}{l}\text { Usabilidade } \\
\text { Eficácia, eficiência e } \\
\text { satisfação em um contexto } \\
\text { de uso específico } \\
\qquad \text { CLASSIFICAÇÃo }\end{array}$}} \\
\hline++ & +- & -+ & - & & & & \\
\hline $\begin{array}{l}\text { Usabilidade Satisfatória } \\
\text { (US) }\end{array}$ & $\begin{array}{l}\text { Permite o Uso com Pequenas } \\
\text { Restrições (PUPR) }\end{array}$ & $\begin{array}{l}\text { Permite o Uso com } \\
\text { Dificuldade (PUD) }\end{array}$ & $\begin{array}{l}\text { Problemas de Usabilidade } \\
\text { Graves (PUG) }\end{array}$ & $\begin{array}{l}\text { US } \\
++\end{array}$ & $\begin{array}{l}\text { PUPR } \\
+-\end{array}$ & $\begin{array}{l}\text { PUD } \\
-+\end{array}$ & PUG \\
\hline \multicolumn{2}{|c|}{$\begin{array}{l}\text { PRINCÍPIO 1: USO EQUITATIVO } \\
\text { O design é útil e comercializável a qualquer grupo de usuários } \\
\text { com habilidades diversas, ou seja, pode ser utilizado por } \\
\text { pessoas com habilidades diversas, evitando segregação ou } \\
\text { discriminação. }\end{array}$} & \multicolumn{6}{|c|}{$\begin{array}{l}\text { 1a fornecer os mesmos meios de utilização para todos os usuários: idênticos sempre que } \\
\text { possível e equivalente quando não for possível; } \\
\text { 1b evitar segregar ou estigmatizar quaisquer usuários; } \\
\text { 1c disposiç̃̃es de segurança: a segurança e a privacidade devem ser igualmente disponíveis } \\
\text { a todos os usuários; } \\
\text { 1d desenvolver um design atraente para todos os usuários; }\end{array}$} \\
\hline \multicolumn{8}{|c|}{$\begin{array}{l}\text { O projeto do edifício deve torná-lo igualmente utilizável por todos, e os meios pelos quais as pessoas possam usar o edifício deve ser o mesmo (por exemplo, } \\
\text { fornecendo um acesso de entrada ao edifício que seja eficiente para todos). Os vários meios fornecidos na edificação devem ser equivalentes em termos de } \\
\text { privacidade e segurança. A edificação nunca deve empregar meios que isolam ou estigmatizam qualquer grupo de usuários ou privilegie um grupo sobre outro } \\
\text { (DANFORD; TAUKE, 2001. p. 21). }\end{array}$} \\
\hline
\end{tabular}

Figura 3: Formulário de avaliação heurística para Elemento 1, sistema de circulação Fonte: Elaborada pelas autoras, 2014

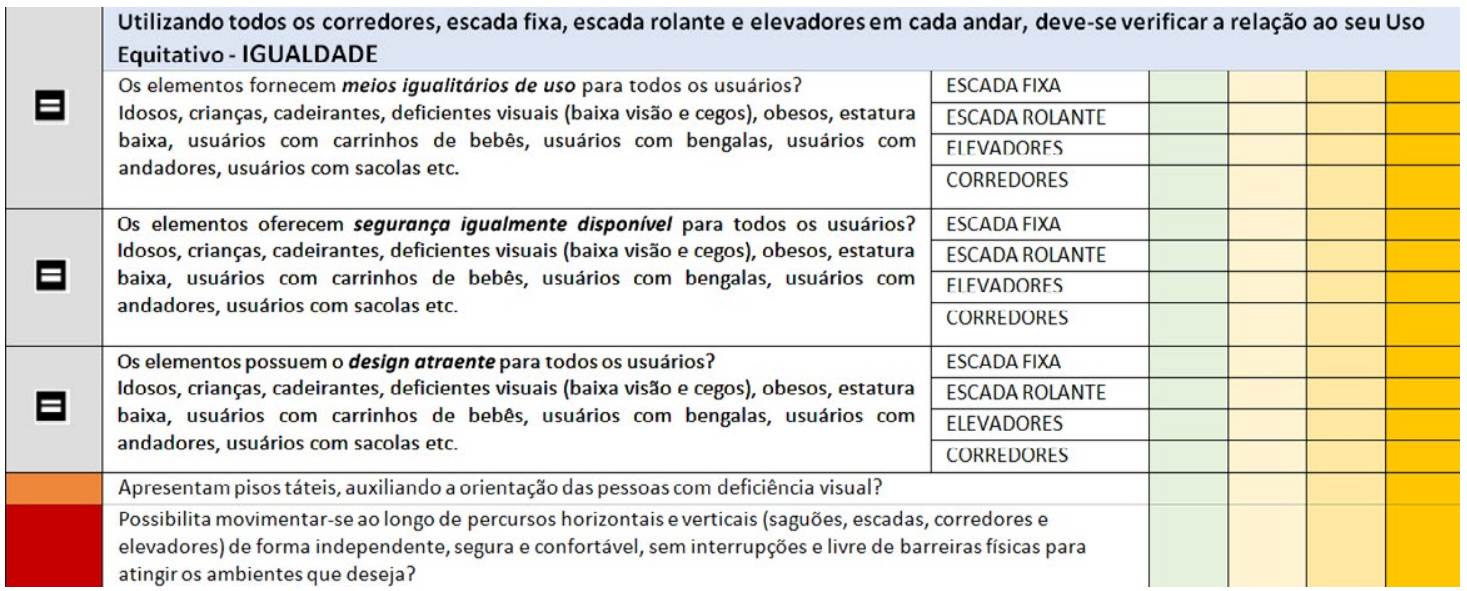

Durante a avaliação heurística das sessões I, II e III, foram anotadas as observações dos avaliadores, podendo eles, assim, acrescentar e referenciar os problemas de usabilidade destacados, pois a apresentação dos dados coletados através dos formulários necessitaria de interpretação à procura de significados mais amplos. Os formulários foram sucessivamente preenchidos relacionando cada Elemento a um Princípio, até completar a análise dos sete Princípios do Desenho Universal para os cinco Elementos definidos.

\section{RESULTADOS E DISCUSSÃO}

Ao término das três sessões, diversos problemas de usabilidade foram encontrados pelos avaliadores. O gráfico com percentuais de problemas de usabilidade resultantes da avaliação heurística do Centro Comercial Planejado é apresentado na Figura 5. Pode-se afirmar que, do maior para o menor grau de problemas, o Elemento 3 (wayfinding) apresentou maiores problemas de usabilidade, seguido pelo Elemento 1 (sistema de circulação), Elemento 4 (obtenção de produtos e serviços), Elemento 2 (entradas e saídas) e Elemento 5 (serviços públicos).
Figura 4: Formulário de avaliação heurística para Elemento 1, sistema de circulação, relacionado ao Princípio 1 do Desenho Universal e componentes da acessibilidade espacial

Fonte: Elaborada pelas autoras, 2014 


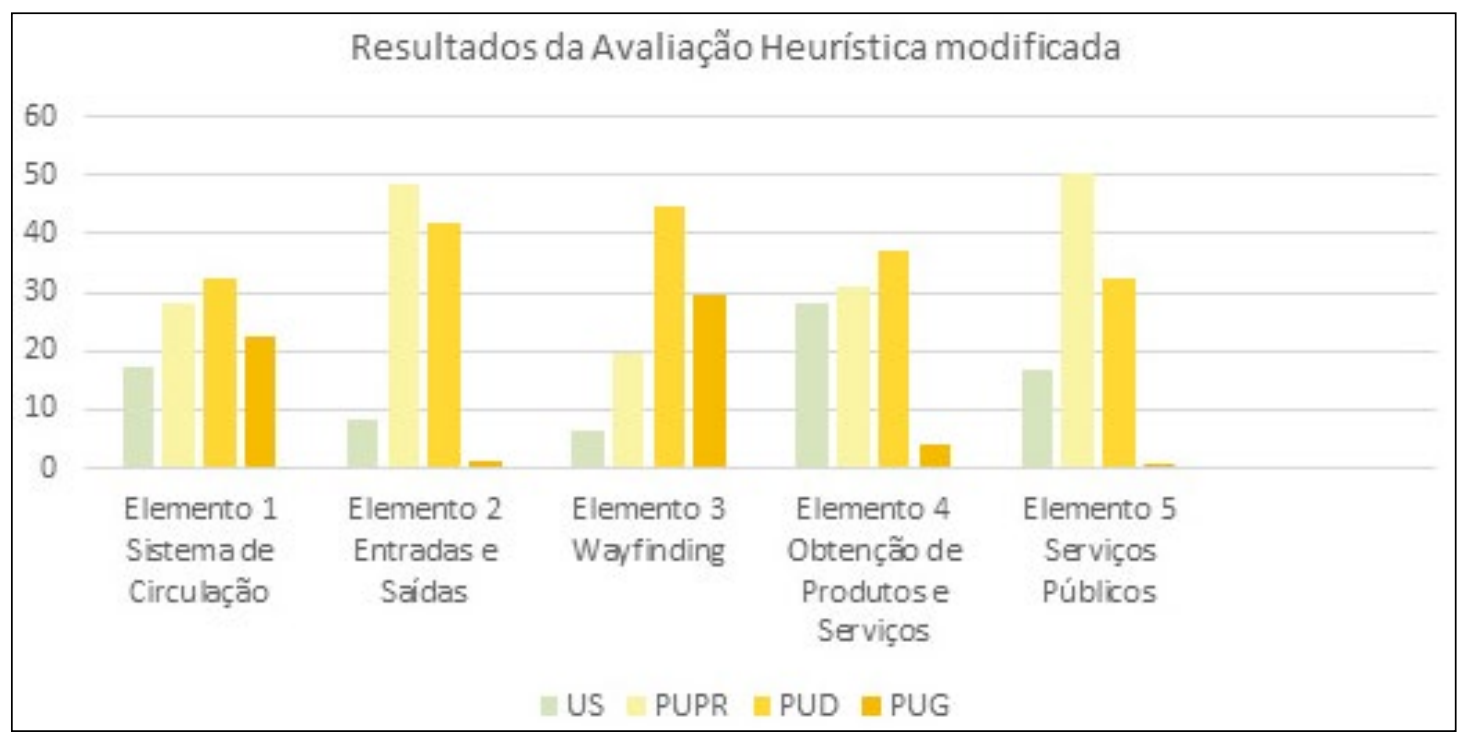

Figura 5: Comparação dos

dados obtidos nas três sessões da avaliação heurística modificada em relação aos Elementos da Cidade Universal

Fonte: Elaborada pelas autoras, 2014
A partir dos resultados, pode-se concluir que o Centro Comercial Planejado atende parcialmente os quesitos relacionados à usabilidade universal. No tangente ao Elemento 3, elementos pictóricos de wayfinding impõem restrições à maioria dos usuários em relação à legibilidade e compreensão do espaço. A inexistência de informação tátil eficiente impossibilita a acessibilidade das pessoas com deficiência visual, usuário com maior grau de problemas de usabilidade. O Elemento 1, sistema de circulação, impõe restrição a um grupo de usuários em relação a alguns acessos: a escada curva apresenta alto grau de restrições e a escada rolante favorece grupos de usuários e impossibilita o acesso de cadeirantes, mães com carrinhos de bebês, usuários de bengalas, idosos, entre outros. 0 layout simétrico propicia falhas na legibilidade e a existência de barreiras físicas dificulta o percurso. A acessibilidade para pessoas com deficiência visual possui restrições, ocasionando graus medianos de problemas de usabilidade. O Elemento 4, obtenção de produtos e serviços, apresenta restrições em relação ao atendimento e circulação nas praças de alimentação, cinema, boliche e parque de diversões, ocasionando graus medianos de problemas de usabilidade. O Elemento 2, entradas e saídas, apresenta problemas em relação a estacionamentos e percursos bem definidos e seguros para todos os usuários, ocasionando graus medianos de problemas de usabilidade. Finalizando, o Elemento 5, serviços públicos, apresenta problemas de configuração espacial e legibilidade, além de problemas em relação ao uso desses espaços, ocasionando graus medianos de problemas de usabilidade.

A avaliação heurística modificada de Afacan e Erbug (2009) utilizou como instrumento de avaliação entrevista aberta que possibilitava ao avaliador maior liberdade na análise do projeto arquitetônico e walkthrough. Cinquenta e três problemas de usabilidade foram identificados pelos avaliadores e classificados em duas categorias: maior e menor. Os maiores problemas de usabilidade foram identificados na sessão I, e os menores, na sessão II-A e III.

Após a aplicação de um pré-teste, verificou-se a necessidade de alterações na estrutura da avaliação heurística. O Quadro 3 apresenta as principais diferenças entre as avaliações utilizadas para compreensão e elucidação em futuras replicações. 
Quadro 3: Comparação entre a avaliação heurística modificada utilizada por Afacan e Erbug (2009) e a utilizada pelo pesquisador

\begin{tabular}{|c|c|c|}
\hline $\begin{array}{l}\text { Avaliação heurística } \\
\text { modificada }\end{array}$ & Afacan e Erbug (2009) & Pesquisadores \\
\hline Estudo de caso & Shopping Center verticalizado. & $\begin{array}{l}\text { Shopping Center com organização } \\
\text { espacial horizontal. }\end{array}$ \\
\hline Cenários & $\begin{array}{l}\text { Componentes da Cidade Universal (DANFORD; } \\
\text { TAUKE, 2001). }\end{array}$ & $\begin{array}{l}\text { Componentes da Cidade Universal } \\
\text { (DANFORD; TAUKE, 2001). }\end{array}$ \\
\hline Heurísticas & Princípios do Desenho Universal. & $\begin{array}{l}\text { Princípios do Desenho Universal } \\
\text { Componentes da acessibilidade espacial. }\end{array}$ \\
\hline Técnicas utilizadas & Entrevista aberta. & Entrevista estruturada. \\
\hline Instrumento de avaliação & Resumo do procedimento. & Formulário a ser preenchido pelo avaliador. \\
\hline Papel do pesquisador & $\begin{array}{l}\text { Pesquisador orienta e acompanha o avaliador para } \\
\text { registrar as observações. }\end{array}$ & $\begin{array}{l}\text { Pesquisador acompanha o avaliador e } \\
\text { registra as observações. }\end{array}$ \\
\hline Grupo de avaliadores & $\begin{array}{l}2 \text { arquitetos (área: arquitetura de interiores); } \\
2 \text { arquitetos (área: projeto arquitetônico); } \\
1 \text { arquiteto (área: planejamento urbano). }\end{array}$ & $\begin{array}{l}1 \text { arquiteto (área: arquitetura de interiores); } \\
2 \text { arquitetos (área: projeto arquitetônico); } \\
1 \text { arquiteto (área: planejamento urbano); } \\
1 \text { engenheiro (área: construção). } \\
\end{array}$ \\
\hline Número de sessões & $\begin{array}{l}3 \text { sessões consecutivas individuais: } \\
\text { Sessão I - realizada no escritório do avaliador. } \\
\text { Sessão II - realizada no shopping center. } \\
\text { Sessão III - realizada no shopping center. }\end{array}$ & $\begin{array}{l}3 \text { Sessões consecutivas em grupo } \\
\text { Sessão I - realizada no shopping center. } \\
\text { Sessão II-A - realizada no shopping center. } \\
\text { Sessão III - realizada no shopping center. }\end{array}$ \\
\hline $\begin{array}{l}\text { Duração das sessões } \\
\text { (tempo) }\end{array}$ & $\begin{array}{l}\text { Sessão I - aproximadamente } 1 \text { hora. } \\
\text { Sessão II - } 4 \text { a } 5 \text { horas. } \\
\text { Sessão III - aproximadamente } 1 \text { hora. }\end{array}$ & $\begin{array}{l}\text { Sessão I - aproximadamente } 2 \text { horas. } \\
\text { Sessão II-A - aproximadamente } 4 \text { horas. } \\
\text { Sessão III - aproximadamente } 50 \text { minutos. }\end{array}$ \\
\hline Usuário & $\begin{array}{l}\text { Avaliação não propõe a participação do usuário no } \\
\text { processo de avaliação. }\end{array}$ & $\begin{array}{l}\text { Avaliação propõe a participação do usuário } \\
\text { no processo de avaliação (Sessão II-B). }\end{array}$ \\
\hline Dados obtidos & $\begin{array}{l}\text { Cinquenta e três problemas de usabilidade foram } \\
\text { identificados pelos avaliadores e classificados em } \\
\text { duas categorias: maior e menor. O autor fornece } \\
\text { uma lista com os problemas de usabilidade, } \\
\text { uma tabela com porcentagem de problemas } \\
\text { encontrados em cada sessão e um gráfico } \\
\text { demonstrando qual avaliador relatou mais } \\
\text { problemas de usabilidade. }\end{array}$ & $\begin{array}{l}\text { A avaliação foi determinada por graus de } \\
\text { problemas de usabilidade e demonstrada } \\
\text { em tabelas e transcrição das observações } \\
\text { dos arquitetos e engenheiro. Através de } \\
\text { gráficos, possibilitou a identificação do } \\
\text { elemento que possui maior problema de } \\
\text { usabilidade. }\end{array}$ \\
\hline
\end{tabular}

Fonte: Elaborado pelas autoras, 2014

O formulário desenvolvido objetivou criar um roteiro definido em conformidade com as heurísticas e classificação dos problemas de usabilidade. Para sua elaboração, foram utilizados os resumos do procedimento utilizado por Afacan e Erbug (2009), nos quais se definem os princípios de Desenho Universal (heurísticas), relacionando-os com considerações projetuais para centros comerciais e utilizando-se das diretrizes dos sete princípios do Desenho Universal como questionamentos em relação aos elementos da Cidade Universal. O formulário focou, em sua análise, a usabilidade universal, ou seja, destacou os elementos a serem analisados e os relacionou da maneira mais eficiente aos princípios do Desenho Universal, possibilitando a compreensão do grau de problemas de usabilidade.

O maior problema detectado no formulário foi em relação aos questionamentos repetidos (diretrizes dos sete princípios) e confusos. O formato apresentado necessita de avaliadores especialistas em Desenho Universal para a compreensão do instrumento, e há necessidade de criação de perguntas mais claras em relação aos princípios do Desenho Universal. O formulário apresentou novas heurísticas - componentes da acessibilidade espacial -, e as perguntas formuladas demonstraram maior clareza aos avaliadores; pode-se concluir, com essa afirmação, que a formulação de novas perguntas, mais objetivas e claras, para os avaliadores se faz necessária, possibilitando o auxílio no entendimento e na redução do formulário, que 
se mostrou muito extenso. Um formulário menor possibilitaria um espaço para registros de observações relevantes ao roteiro a serem realizadas pelo avaliador, evitando que o compartilhamento oral dos demais avaliadores influencie as observações do participante. A escala de classificação dos problemas de usabilidade apresentada no formulário deve ser repensada, pois se apresenta muito extensa. Há necessidade de criar uma escala de classificação referente ao impedimento de uso por algum usuário. Sugeremse, então, testes de outras escalas.

Em relação ao procedimento das sessões, algumas considerações devem ser pontuadas:

- o procedimento utilizado por Afacan e Erbug (2009) demonstra-se mais adequado em relação à realização da avaliação individual com o especialista. A avaliação em grupo, mesmo com preenchimento individual do formulário, influencia as respostas dos avaliadores devido à verbalização dos problemas, interferindo nos dados obtidos.

- a sessão I apresentou grande eficácia na avaliação, mas necessita de complementação da sessão II-A. As especificações falhas em projeto, a falta de detalhamento e alguns elementos que não são apontados no projeto arquitetônico, como pessoas circulando pelo espaço, formação de filas, alcance visual, mapas, placas, entre outros, necessitam da avaliação no local, ou seja, avaliação pós-ocupação.

- a sessãoIIInão apresentou eficácia no preenchimento dosformulários(os avaliadores repetiram as respostas), mas encorajou um pequeno debate e a formulação de propostas para melhoria do projeto arquitetônico. Para uma replicação da avaliação heurística utilizando o formulário proposto, sugere-se ao futuro pesquisador a exclusão da última sessão. Se for aplicada, a sessão III deve ser desenvolvida como uma revisão dos problemas encontrados e um debate em grupo dos resultados. Deve ser aprimorada, permitindo a consolidação dos resultados, ou seja, os avaliadores devem revisar os problemas encontrados e desenvolver recomendações de soluções através de relatórios.

- a aplicação da sessão II-B, walkthrough com usuários, possibilitou a verificação dos problemas de usabilidade em relação aos mesmos componentes da Cidade Universal, ou seja, elemento 3 (wayfinding) e elemento 1 (sistema de circulação). Verificou-se que alguns problemas de usabilidade destacados como graves pelo grupo de especialistas não são considerados com a mesma gravidade pelo usuário consumidor; por isso, há necessidade de maior investigação, possibilitando uma avaliação do ambiente construído na rotina diária desse usuário específico. O walkthrough com usuário deve ser ampliado para um maior número de usuários, como pessoas com deficiência auditiva ou visual, e inclusão do usuário que trabalha no Centro Comercial Planejado, pois os resultados seriam outros.

A inexistência de especialistas em usabilidade no campo de arquitetura e urbanismo e a falta de especialistas em Desenho Universal na região acarretaram limites na seleção do grupo avaliador. Para uma futura replicação, sugere-se a seleção de um grupo de especialistas em usabilidade com grande conhecimento em Desenho Universal e acessibilidade espacial.

Buscando aprimorar o conteúdo do formulário aplicado, foram realizados questionamentos aos especialistas participantes da avaliação heurística em relação à usabilidade da ferramenta de avaliação e seu conteúdo. Algumas afirmações foram bem importantes para a discussão. Seguem algumas considerações dos especialistas:

- a avaliação de usabilidade do espaço construído foi considerada muito relevante, sendo que o termo não era conhecido no contexto de arquitetura e urbanismo. 
- houve dificuldade em não focar apenas no cumprimento da norma NBR 9050:2015 (ASSOCIAÇÃO BRASILEIRA DE NORMAS TÉCNICAS, 2015), que trata da "acessibilidade a edificações, mobiliário, espaços e equipamentos urbanos" e contemplar todos os usuários.

- houve dificuldade de compreensão dos princípios do Desenho Universal, pois são generalistas. A análise individual dos princípios é complexa, pois muitas vezes as análises se repetem e se complementam.

- houve exigência de grande conhecimento sobre Desenho Universal e usabilidade para avaliação e preenchimento do formulário. Os especialistas chegaram à conclusão de que os princípios do Desenho Universal e usabilidade estão sendo pouco aplicados e compreendidos pelos profissionais de arquitetura e urbanismo, o que torna a tomada de decisão no processo de projeto de construção universal uma tarefa complexa.

- a avaliação heurística proporcionou uma reflexão sobre a concepção universal do espaço construído no processo de projeto e as exigências dos sete princípios do Desenho Universal.

- a escolha de um especialista que visitou o shopping pela primeira vez foi muito importante para a troca de informações entre os avaliadores.

- as sessões não devem ser realizadas consecutivamente, pois os avaliadores demonstraram cansaço e a última avaliação foi muito prejudicada.

- O método de avaliação heurística modificado em conformidade com os princípios do Desenho Universal e acessibilidade espacial proporciona uma análise aprofundada dos elementos de uma Cidade Universal, possibilitando ao avaliador um direcionamento para identificar, em cenários definidos, problemas de usabilidade de baixa, média e alta severidade. Além da exigência da competência dos avaliadores, a estratégia de avaliação através de formulários apresenta eficácia e eficiência, conferindo usabilidade no processo de avaliação.

\section{CONCLUSÕES}

A pesquisa atingiu seus objetivos ao aplicar uma avaliação heurística modificada definida por Afacan e Erbug (2009), a qual é realizada por especialistas interdisciplinares em acessibilidade. A interligação de conhecimentos de Desenho Universal e acessibilidade espacial com conceitos de usabilidade possibilitaram interações entre o usuário e o espaço físico em grande amplitude. A análise em relação ao potencial de aplicação é positiva, pois assegura uma investigação aprofundada dos elementos de uma Cidade Universal, proporcionando ao avaliador um direcionamento para identificar, em cenários definidos, problemas de usabilidade de baixa, média e alta severidade.

A avaliação heurística apresenta-se como um método muito eficaz para a redução de problemas de usabilidade que resultam de aplicações malsucedidas de acessibilidade no processo de projeto. A decisão projetual em relação ao Desenho Universal é complexa e, consequentemente, uma ferramenta que direciona o avaliador à análise e avaliação do projeto em fase de concepção e pós-ocupação, sob os princípios do Desenho Universal, corrobora decisões assertivas em um ambiente construído para pessoas com diferentes habilidades; ou seja, o método de avaliação heurística interdisciplinar pode assegurar uma taxa de erro reduzida para o uso universal de ambientes construídos. É um método de inspeção rápido, de baixo custo e de fácil implementação.

A pesquisa contribuiu para o aperfeiçoamento do método de avaliação baseado em heurísticas, através da melhoria do instrumento de avaliação 
de usabilidade no ambiente construído e detectando falhas por meio de sua aplicação em cenários pré-determinados. O formulário de avaliação heurística modificada necessita de ajustes em relação à simplificação das informações a serem obtidas, através da correlação entre os princípios do Desenho Universal e acessibilidade espacial, evitando repetição de questionamentos e proporcionando interpelação objetiva e clara. Recomendam-se novos testes de escala para classificação dos problemas de usabilidade e incorporação de espaço para anotações de observações dos avaliadores.

A associação do método de avaliação heurística ao método de inspeção ou percurso pluralístico demonstra-se eficaz para humanizar o processo e confirmar algumas considerações levantadas pelos especialistas. A associação só poderá ser realizada em edificações existentes, pois necessita dos cenários de tarefas para verificação de sua usabilidade, ou seja, eficácia, eficiência e satisfação em relação ao ambiente construído. Recomenda-se a seleção de usuários com maior número de habilidades diferenciadas para ampliação de resultados e verificação de usabilidade.

A identificação de problemas maiores e menores de usabilidade surge como gerador na elaboração de diretrizes projetuais que possam ser utilizadas na concepção de centros comerciais planejados e outras edificações complexas. A compreensão do conceito de usabilidade mais aprofundada é uma contribuição relevante ao processo de projeto, sendo essencial para aplicação em projetos arquitetônicos, permitindo confrontar metas e expectativas formuladas e problemas de usabilidade. Os conhecimentos dessas áreas e de suas possíveis aplicações permitem uma análise acerca das soluções que podem criar facilidades ou restrições ao desempenho humano. O aspecto do desempenho de usabilidade significa o quão eficiente e eficaz é, para um usuário, a execução de uma tarefa para alcançar alguns objetivos pretendidos pelo uso de um produto. Perante essa constatação, podemos afirmar que a inclusão de disciplinas referentes à usabilidade e ao Desenho Universal se fazem necessárias para a formação do arquiteto e urbanista. A motivação para análise e adoção de novas práticas projetuais universais identificará possibilidades de intervenção para promover melhorias no processo de projeto e, consequentemente, nas edificações.

\section{REFERÊNCIAS}

AFACAN, Y.; ERBUG, C. An interdisciplinary heuristic evaluation method for universal building design. Applied Ergonomics, Amsterdam, n. 40, p. 731-744, 2009.

ASSOCIAÇÃO BRASILEIRA DE NORMAS TÉCNICAS. NBR 9241-11: Requisitos ergonômicos para trabalho de escritórios com computadores parte 11: orientações sobre usabilidade. Rio de Janeiro: ABNT, 2002. 21 p.

NBR ISO/IEC 9126-1991:

engenharia de software - qualidade de produto - parte 1: modelo de qualidade. Rio de Janeiro: ABNT, 2003. 21p.

NBR 9050/2015: acessibilidade a edificações, mobiliário, espaços e equipamentos urbanos. Rio de Janeiro: ABNT, 2015. 162p.

BACON, E. N. Design of cities. New York: Penguin, 1976. 336p.

BARBOSA, S. D. J.; SILVA, B. S. Interação humano-computador. Rio de Janeiro: Elsevier, 2010. 384p.
BEECHER, V.; PAQUET, V. Survey instrument for the universal design of consumer products. Applied Ergonomics, Amsterdam, n. 36, p. 363-372, 2005.

BLOWER, H. C. S. O lugar do ambiente na educação infantil: estudo de caso na creche Doutor Paulo Niemeyer. 2008. 187f. Dissertação (Mestrado em Arquitetura) Universidade Federal do Rio de Janeiro, Rio de Janeiro-RJ, 2008.

BRASIL. Decreto no 5.296, de 2 de dezembro de 2004. Regulamenta as Leis no 10.048 , de 8 de novembro de 2000 , que dá prioridade de atendimento às pessoas que especifica, e 10.098, de 19 de dezembro de 2000, que estabelece normas gerais e critérios básicos para a promoção da acessibilidade das pessoas portadoras de deficiência ou com mobilidade reduzida, e dá outras providências. Diário Oficial da União, Brasília, DF, 3 dez. 2004. 
CAMBIAGHI, S. S.; CARLETTO, A. C. Desenho universal: um conceito para todos. Mara Gabrilli, [S.I.], 2008.

CARLIN, F. Acessibilidade espacial em shopping center: um estudo de caso. 2004. 191f. Dissertação (Mestrado em Engenharia da Produção) - Universidade Federal de Santa Catarina, Florianópolis, 2004.

CASTELNOU, A. Arquitetura londrinense: expressões de intenção pioneira. Londrina: AtritoArt, 2002. 346p

CULLEN, G. Paisagem urbana. Lisboa: Edições 70, 1971. 202p.

DANFORD, G. S.; TAUKE, B. (Eds.). Universal design New York. New York: Vanguard Direct, 2001. 124p.

DEMIRBILEK, O.; DEMIRKAN, H. Universal product design involving elderly users: a participatory design model. Applied Ergonomics, Amsterdam, n. 35, p. 361-370, 2004.

DIAS, C. Usabilidade na WEB: criando portais mais acessíveis. 2. ed. Rio de Janeiro: Alata Books, 2007. 296p.

DISCHINGER, M.; ELY, V. H. M. B.; PIARDI, S. M. D. G. Promovendo acessibilidade espacial nos edifícios públicos: programa de acessibilidade às pessoas com deficiência ou mobilidade reduzida nas edificações de uso público. Florianópolis: MPSC, 2012. 161p.

FERREIRA, A. B. H. Miniaurélio: o minidicionário da Língua Portuguesa. 7. ed. Curitiba: Positivo, 2008. 896p.

HETZBERGER, H. Lições de arquitetura. São Paulo: Martins Fontes, 1999. 272p.

HÖLSCHER, C. et al. Up the down staircase: wayfinding strategies in multi-level buildings. Journal Environmental Psychology, Amsterdam, n. 26, p. 284-299, 2006.

JORDAN, P. W. Designing pleasurable products: an introduction to the New Human Factors. London: Taylor \& Francis, 2000. 224p

KASPER, A. A.; LOCH, M. V. P.; PEREIRA, V. L. D. V. A abordagem do espaço físico inclusivo sob a ótica da usabilidade e do design de interação. In: CONGRESSO BRASILEIRO DE ENGENHARIA DE PRODUÇÃO, 2., 2830 nov. 2012, Ponta Grossa. Anais... Ponta Grossa: Universidade Tecnológica Federal do Paraná, 2012.

KEITH, A. The application of usability concepts in the built environment. Journal of Facilities Management, Salford, v. 4, n. 4, p. 262-270, 2006

KOOHANG, A. Expanding the concept of usability. Informing Science Journal, [S.I.], v. 7, p. 129-141, 2004. Disponível em: <https:// goo.gl/gDrmas> Acesso em: 4 jun. 2013.

KOWALTOWSKI, D. C. C. K. et al. Reflexão sobre metodologias de projeto arquitetônico. Ambiente Construído, Porto Alegre, v. 6, n. 2, p. 7-19, 2006.

LYNCH, Kevin. A imagem da Cidade. 2. ed. São Paulo: WMF Martins Fontes, 2010. 227p.

MACE, R. et al. The Principles of Universal design, version 2.0. Washington, DC: The National Institute on Disability and Rehabilitation Research, 4 jan. 1997.

NIELSEN, J. Usability engineering. San Francisco: Morgan Kaufmann, 1993. 340p.

. Heuristic evaluation. In: MACK, R.; NIELSEN, J. (Eds.). Usability inspection methods. New York: John Wiley \& Sons, 1994. p. 25-62.

How to conduct a heuristic evaluation. Nielsen Norman Group, Fremont, 1ำ jan. 1995a.

10 usability heuristics for user interface design. Nielsen Norman Group Fremont, 1ํ jan. 1995b.

NIELSEN, J.; LORANGER, H. Usabilidade na Web: projetando websites com qualidade. Rio de Janeiro: Campus-Elsevier, 2007. 406p.

NIELSEN, J.; MOLICH, R. Heuristic evaluation of user interfaces. In: SIGCHI CONFERENCE ON HUMAN FACTORS IN COMPUTING SYSTEMS, 1-5 abr. 1990, Seattle. Proceedings.. Nova lorque: ACM, 1990. p. 249-256.

NORBERG-SCHULZ, C. Existencia, espacio y arquitectura. Barcelona: Blume, 1975. 145p.

PAULA, K. C. L.; SANTANA, E. P.; DUARTE, C. R. Estudo cinestésicos: uma experiência projetual em torno do "Exercício Experimental da Liberdade". In: DUARTE, C. R.; RHEINGANTZ, P. A.; AZEVEDO, G.; BRONSTEIN, L. (Orgs.). O lugar do projeto: no ensino e na pesquisa em arquitetura e urbanismo. Rio de Janeiro: PROARQ, 2007. 536p. p. 203-215.

PREISER, W. F. E. Das políticas públicas à prática profissional eà pesquisa de avaliação de desempenho voltada para o desenho universal. In: ORNSTEIN, S. W.; PRADO, A. R. A.; LOPES, M. E. (Orgs.). Desenho universal: caminhos da acessibilidade no Brasil. São Paulo: Annablume, 2010. p. 19-32.

REIS, A. T:; LAY, M. C. D. Percepção e análise dos espaços: Desenho Universal. In: ORNSTEIN, S. W.; PRADO, A. R. A.; LOPES, M. E. (Orgs.). Desenho universal: caminhos da acessibilidade no Brasil. São Paulo: Annablume, 2010. p. 105-115.

RHEINGANTZ, P. A. et al. Observando a qualidade do lugar: procedimentos para 
a avaliação pós-ocupação. Rio de Janeiro: UFRJ-FAU, 2009. 117p. (Coleção PROARQ).

SILVA, A. H. et al. Acessibilidade: mobilidade acessível na cidade de São Paulo. São Paulo: CPA: Secretaria da Pessoa com Deficiência e Mobilidade Reduzida, 2008. 206p.

SOLÀ-MORALES RUBIÓ, I. Territorios. Barcelona: GG, 2002. 207p.

TANAKA, E. H. Método baseado em heurísticas para avaliação de acessibilidade em sistemas de informação. 2009. 100f. Tese (Doutorado em Computação) - Universidade Estadual de Campinas, Campinas, 2009.

VOORDT, T. J. M.; WEGEN, H. B. R. Arquitetura sob o olhar do usuário: programas de necessidades, projeto e avaliação de edificações. São Paulo: Oficina de Textos, 2013. 237p.

ZEVI, B. Saber ver a arquitetura. 6. ed. São Paulo: WMF Martins Fontes, 2009. 286p. 